\title{
316.
}

\section{NOTE ON THE SOLUTION OF AN EQUATION OF THE FIFTH ORDER.}

[From the Philosophical Magazine, vol. xxIII. (1862), pp. 195, 196.]

This Note was in answer to Mr Jerrard's paper "Remarks on Mr Cayley's Note," Phil. Mag. vol. xxI. pp. 348-350, referring to the foregoing paper 310 . 